\title{
Hearing loss in Norwegian adults with achondroplasia
}

\author{
Svein O. Fredwall ${ }^{1,2^{*}}$ (D) Björn Åberg ${ }^{3}$, Hanne Berdal ${ }^{3}$, Ravi Savarirayan ${ }^{4}$ and Jorunn Solheim ${ }^{3}$
}

\begin{abstract}
Background: Achondroplasia is the most common form of disproportionate skeletal dysplasia. The condition is caused by a mutation in the FGFR3 gene, affecting endochondral bone growth, including the craniofacial anatomy. Recurrent otitis media infections, chronic middle ear effusion, and hearing loss are common in children with achondroplasia, but few studies have investigated hearing loss in adults with this condition.
\end{abstract}

Objectives: This population-based study investigated the prevalence, severity, and type of hearing loss in Norwegian adults with achondroplasia.

Methods: We collected data on 45 adults with genetically confirmed achondroplasia: 23 men and 22 women, aged 16-70 years. All participants underwent a comprehensive audiologic assessment, including medical history, pure-tone audiometry, speech audiometry, and impedance audiometry. According to the Global Burden of Disease classification, pure-tone average $\geq 20$ decibel hearing level ( $\mathrm{dB} \mathrm{HL}$ ) was considered clinically significant hearing loss.

Results: Insertion of ventilation tubes had been performed in 44\% (20/45) of the participants, 49\% (22/45) had a history of adenoidectomy, while 20\% (9/45) used hearing aids. Hearing loss in at least one ear was found in 53\% (24/45) of the participants; in 57\% (13/23) of the men and 50\% (11/22) of the women. In the youngest age group (age 16-44 years), 50\% (14/28) had hearing loss, although predominantly mild (20-34 dB HL). An abnormal tympanometry (Type B or C) was found in 71\% (32/45) of the participants. The majority (15/24) had conductive hearing loss, or a combination of conductive and sensorineural hearing loss (8/24).

Conclusions: Adults with achondroplasia are at increased risk of early hearing loss. Our findings underline the importance of a regular hearing assessment being part of standard care in achondroplasia, including adolescents and young adults. In adult patients diagnosed with hearing loss, an evaluation by an otolaryngologist should be considered, and the need for hearing aids, assistive listening devices, and workplace and educational accommodations should be discussed.

Clinical trial registration ClinicalTrials.gov identifier NCT03780153.

Keywords: Hearing loss, Audiometry, Tympanometry, Impedance audiometry, Craniofacial abnormalities

*Correspondence: svfred@sunnaas.no

${ }^{1}$ TRS National Resource Centre for Rare Disorders, Sunnaas Rehabilitation Hospital, 1450 Nesodden, Norway

Full list of author information is available at the end of the article

\section{Introduction}

Achondroplasia is the most common form of disproportionate skeletal dysplasia, affecting more than 250,000 individuals worldwide [1]. The condition is caused by a mutation in the Fibroblast Growth Factor Receptor 3 (FGFR3) gene, affecting endochondral bone growth, including the craniofacial anatomy [2]. Individuals with craniofacial syndromes are at high risk of original author(s) and the source, provide a link to the Creative Commons licence, and indicate if changes were made. The images or other third party material in this article are included in the article's Creative Commons licence, unless indicated otherwise in a credit line to the material. If material is not included in the article's Creative Commons licence and your intended use is not permitted by statutory regulation or exceeds the permitted use, you will need to obtain permission directly from the copyright holder. To view a copy of this licence, visit http://creativecommons.org/licenses/by/4.0/. The Creative Commons Public Domain Dedication waiver (http://creativeco mmons.org/publicdomain/zero/1.0/) applies to the data made available in this article, unless otherwise stated in a credit line to the data. 
middle ear disease and hearing loss [3-5]. In achondroplasia, midface hypoplasia, short Eustachian tubes, small pharynx, and the relative enlargement of tonsils and/or adenoids, are predisposing factors for recurrent upper airway infections and chronic middle ear effusion [3, 6-9]. Prior studies on children with achondroplasia have reported that up to $70 \%$ have experienced acute or recurrent otitis media [9-11], giving increased risk of persistent middle ear disease and permanent hearing loss $[5,12]$. Hearing loss has been reported in 50-70\% of children with achondroplasia $[6,7,9,13]$. However, few studies have investigated hearing loss in adults with this condition, and no population-based studies exists $[6,14]$.

Tunkel et al. reported that $55 \%$ out of 28 adults with achondroplasia screened at a patient support meeting failed hearing screening in one or both ears, and 39\% had abnormal tympanometry [13]. Hunter et al. reported that $38 \%$ of the adult study population $(n=43)$ had hearing loss, but audiograms were not available in all [9]. Glass et al. conducted pure-tone audiometry and tympanometry in 28 adults with achondroplasia [15]. Hearing loss was found in $61 \%$ of the participants, of whom the majority had conductive hearing loss, and $51 \%$ had an abnormal middle ear function [15].

According to the Global Burden of Disease Study 2019, hearing loss was the third largest cause of disability worldwide, with an overall global prevalence of 19\% [16]. In Europe, the overall prevalence was $14 \%$. The hearing loss was largely caused by ageing, and $62 \%$ of those with impaired hearing were older than 50 years [16]. In the large population-based Norwegian HUNT4 Hearing study $(\mathrm{n}=28,339)$, conducted between 2017 and 2019, $3 \%$ in the age group $20-44$ years had hearing loss, $15 \%$ in the age group $45-64$ years, and $64 \%$ in the age group over 64 years [17]. In children, hearing loss can cause speech delay and learning problems, and educational attainments might be compromised [5, 18-20]. In adults, hearing loss impairs communication, and may cause social isolation, withdrawal from society, reduced employment opportunities, limitations in activity, and reduced quality of life [16, 18, 20-22].

Currently, there are no widely accepted recommendations for hearing assessment in adolescents or adults with achondroplasia. In the recently revised recommendations on Health Supervision for People with Achondroplasia (2020), provided by the American Academy of Pediatrics, the recommendation of a formal routine hearing assessment in children, ideally on an annual basis, has been extended to also include adolescents and adults [23]. Other guidelines recommend a routine assessment of hearing in early childhood at the time of diagnosis and at age 5 years, and further assessment if there is a speech delay, suspicion of hearing difficulties, or signs or symptoms of middle ear disease $[10,12]$.

In the present study, we conducted a comprehensive audiologic assessment to investigate the prevalence, severity, and type of hearing loss in Norwegian adults with achondroplasia.

\section{Methods \\ Study design and population}

This cross-sectional study was part of The Norwegian Adult Achondroplasia Study, a population-based study conducted between 2017 and 2019 on communitydwelling, Caucasian adults, aged 16 years or older, living in Norway [24]. Details of the recruitment process, and inclusion and exclusion criteria in The Norwegian Adult Achondroplasia Study, have been described elsewhere [24].

\section{Data collection and clinical measurements}

A medical history was obtained in a face-to-face interview, including history of otitis media, upper airway infections, prior upper airway surgery, prior diagnosis of impaired hearing, and the use of hearing aids. Participants were also asked whether they received any regular follow-up for hearing loss. Demographic and anthropometric data were collected from The Norwegian Adult Achondroplasia Study [24]. All hearing measurements were conducted at the hearing central at Lovisenberg Diaconal Hospital by an experienced audiologist (JS). The measurements were performed under standardized conditions, in accordance with current international reference standards, and included pure-tone audiometry, speech audiometry, and impedance audiometry. Before the tests, all participants underwent an otomicroscopic examination with photo documentation by an otolaryngologist (HB) or an otosurgeon (BÅ). An OTOsuite audiometer (by OTOmetrics AS) was used for hearing tests. Titan Imp 440 (by Interacoustics AS) was used for impedance audiometry.

\section{Pure-tone audiometry}

Air- and bone-conducted pure-tone thresholds were obtained to measure hearing sensitivity, and provide diagnostic information regarding severity, type and configuration of hearing loss. Pure-tone thresholds were measured separately for the left and right ear and in accordance with the International Organization for Standardization (ISO 8253-1:1989). Pure tones for the frequencies $0.25,0.5,1,2,3,4,6$ and $8 \mathrm{kHz}$ were obtained for the air conduction test, and the frequencies $0.25,0.5$, $1,2,3$ and $4 \mathrm{kHz}$ for the bone conduction test. Better ear refers to the subject's better ear when comparing the pure 
tone average (PTA) of the frequencies $0.5,1,2$ and $4 \mathrm{kHz}$ of the left and the right ear (BE PTA4).

\section{Speech audiometry}

Speech audiometry was carried out to assess speech intelligibility and discrimination, and to crosscheck the results obtained by pure-tone audiometry. A Norwegian Speech Audiometry set ("HiST speech audiometry") was used for speech recognition measurement [25]. The test set consists of three-word utterances of the form numeral-adjective-noun. Speech audiometry was performed according to current reference standards (NS-EN ISO 8253-3/ISO 8253-3:1996).

\section{Impedance audiometry}

Impedance audiometry (tympanometry and stapedius reflex test) was conducted to determine the pressure in the middle ear, evaluate acoustic reflex pathways and tension of the tympanic membrane. The test was also used to distinguish a conductive from a sensorineural hearing loss.

The tympanometry results were displayed as a graph showing compliance, gradient and pressure according to normative values, and was categorized as Type A (normal), Type B (flat, clearly abnormal) or Type C (significantly negative pressure in the middle ear, possible indicative of pathology) [26]. For further statistical analyses, the tympanometry categories were dichotomized to normal (Type A) or abnormal (Types B or C).

Stapedius reflex test was measured both ipsilateral and contralateral. We measured the contraction and thresholds for activation of the stapedius in response to stimuli of $0.5,1,2$, and $4 \mathrm{kHz}$, at intensities of $70-115$ decibel (dB) sound pressure level. The outcome was dichotomized to normal or abnormal for one or both ears [27].

\section{Type of hearing loss}

Type of hearing loss was categorized as (a) normal hearing/no hearing loss, (b) conductive hearing loss, (c) sensorineural hearing loss, or (d) mixed hearing loss. A conductive hearing loss was defined as air-bone gaps larger than $\geq 15 \mathrm{~dB}$ at one frequency or $\geq 10 \mathrm{~dB}$ at two frequencies [28]. A sensorineural hearing loss was defined as a hearing threshold $\geq 20 \mathrm{~dB}$ hearing level ( $\mathrm{dB}$ $\mathrm{HL}$ ), but with an air-bone gap $<15 \mathrm{~dB}$ at one frequency or $<10 \mathrm{~dB}$ at two frequencies. Mixed hearing loss was defined as a combination of conductive and sensorineural components.

\section{Hearing thresholds and severity of hearing loss}

Severity of hearing loss was defined according to the Global Burden of Disease classification: normal hearing: < $20 \mathrm{~dB} \mathrm{HL}$; mild hearing loss: 20.0-34.9 dB HL; moderate hearing loss: 35.0-49.9 dB HL; moderately severe hearing loss: 50.0-64.9 dB HL; severe hearing loss: 65.0-79.9 dB HL; profound hearing loss: 80-94.9 dB HL; complete or total hearing loss: $\geq 95 \mathrm{~dB}$ HL $[22,29]$. Disabling hearing loss was defined as $\geq 35 \mathrm{~dB}$ HL in the better ear (BE PTA4) [18, 30].

\section{Statistical analyses}

Descriptive statistics are presented as frequencies (n) with percentages (\%) for proportions, or means with standard deviation (SD) for continuous variables. Independent sample t-tests were used to compare differences between continues variables. Continuity corrected chi-squared tests were used for comparing proportions (using the "prop. Test" R function). Confidence intervals for proportions was found using the Exact Binominal Test (applying the "binom.test" R function). Statistical significance was set to $\mathrm{p}<0.05$ (two-sided). Statistical analyses was performed using the Statistical Package for Social Sciences (SPSS) version 26 (IBM Corp., Armonk, New York), and R version 3.6.1.

\section{Results \\ Study population and medical history}

Out of the 50 participants in The Norwegian Adult Achondroplasia Study, 45 were included in the present study: 23 men and 22 women. Those five not included were all visited in their homes due to impaired health [24], making standardized hearing measurements impossible. All participants had genetically confirmed achondroplasia [24]. Mean age was 38 years, with a range from 16 to 70 years, $73 \%$ (33/45) were single/lived alone, and $62 \%(28 / 45)$ were currently working or were students (Table 1). Insertion of ventilation tubes had been performed in $44 \%(20 / 45)$ of the participants, $49 \%(22 / 45)$ had a history of adenoidectomy, while $20 \%$ (9/45) used hearing aids. Nine participants (20\%) reported to have regular follow-up by an otolaryngologist. Except for height, there were no significant differences in the characteristics between men and women with achondroplasia (Table 1).

\section{Hearing loss in adults with achondroplasia}

Hearing loss ( $\geq 20 \mathrm{~dB}$ HL) in at least one ear was found in $53 \%(24 / 45)$ of the participants: in $57 \%(13 / 23)$ of the men and $50 \%(11 / 22)$ of the women (difference 7\%, 95\% confidence interval -27 to $40 \%, \mathrm{p}=0.89)$. Unilateral hearing loss was found in $11 \%(5 / 45)$, while $42 \%(19 / 45)$ had bilateral hearing loss (Table 2). The majority (18/24) had mild hearing loss (20-34 dB HL). In the youngest age group (age 16-44 years), 50\% (14/28) had hearing loss, although predominantly mild. The speech audiometry 
Table 1 Characteristics of adult participants with achondroplasia

\begin{tabular}{|c|c|c|c|c|}
\hline Variables & $\begin{array}{l}\text { All } \\
(n=45)\end{array}$ & $\begin{array}{l}\text { Men } \\
(n=23)\end{array}$ & $\begin{array}{l}\text { Women } \\
(n=22)\end{array}$ & Pvalue ${ }^{a}$ \\
\hline Age, years, mean (SD) & $37.7(16.6)$ & $39.1(17.6)$ & $36.2(15.8)$ & 0.56 \\
\hline Height, cm, mean (SD) & $133.1(9.1)$ & $137.0(8.7)$ & $129.1(7.8)$ & 0.002 \\
\hline Variables & $\mathrm{N}(\%)$ & $\mathrm{N}(\%)$ & $\mathrm{N}(\%)$ & \\
\hline Single/living alone & $33(73)$ & $17(74)$ & $16(73)$ & 1.0 \\
\hline Working ${ }^{b}$ or student & $28(62)$ & $13(57)$ & $15(68)$ & 0.54 \\
\hline \multicolumn{5}{|l|}{ Medical history } \\
\hline Acute otitis in childhood & $37(82)$ & $17(74)$ & $20(91)$ & 0.24 \\
\hline Acute otitis in adulthood & $10(22)$ & $5(22)$ & $5(23)$ & 1.0 \\
\hline History of ventilation tubes & $20(44)$ & $11(48)$ & $9(41)$ & 0.77 \\
\hline Adenoidectomy & $22(49)$ & $12(52)$ & $10(46)$ & 0.77 \\
\hline Currently using hearing aid & $9(20)$ & $4(17)$ & $5(23)$ & 0.72 \\
\hline
\end{tabular}

SD standard deviation

a Independent sample t test for continuous variables, and Fisher's exact test for proportions

${ }^{b}$ Working full time, or part time $\geq 50 \%$

Table 2 Hearing loss in adults with achondroplasia, by age groups

\begin{tabular}{|c|c|c|c|c|}
\hline \multirow[t]{2}{*}{ Age groups, years } & $\begin{array}{l}\text { All } \\
(\mathrm{N}=45)\end{array}$ & $\begin{array}{l}16-44 y \\
(n=28)\end{array}$ & $\begin{array}{l}45-64 y \\
(n=14)\end{array}$ & $\begin{array}{l}>64 y \\
(n=3)\end{array}$ \\
\hline & $\mathrm{N}(\%)$ & $\mathrm{N}(\%)$ & $\mathrm{N}(\%)$ & $\mathrm{N}(\%)$ \\
\hline \multicolumn{5}{|c|}{ Hearing loss in at least one ear ${ }^{a}$} \\
\hline Mild (20-34 dB) & $18(40)$ & $12(43)$ & $6(43)$ & $0(0)$ \\
\hline Disabling ( $\geq 35 \mathrm{~dB})$ & $6(13)$ & $2(7)$ & $1(7)$ & $3(100)$ \\
\hline \multicolumn{5}{|l|}{ Unilateral hearing loss ${ }^{\mathrm{a}}$} \\
\hline Mild (20-34 dB) & $3(7)$ & $3(11)$ & $0(0)$ & (0) \\
\hline Disabling ( $\geq 35 \mathrm{~dB})$ & $2(4)$ & $2(8)$ & $0(0)$ & $(0)$ \\
\hline \multicolumn{5}{|c|}{ Hearing loss in the better ear ${ }^{b}$} \\
\hline Mild (20-34 dB) & $15(33)$ & $9(32)$ & $6(43)$ & $0(0)$ \\
\hline Disabling ( $\geq 35 \mathrm{~dB}$ ) & $4(9)$ & $0(0)$ & $1(7)$ & $3(100)$ \\
\hline \multicolumn{5}{|c|}{ Abnormal tympanometry ${ }^{c}$} \\
\hline Unilateral & $8(18)$ & $5(18)$ & $3(21)$ & $0(0)$ \\
\hline Bilateral & $24(53)$ & $12(43)$ & $9(64)$ & $3(100)$ \\
\hline \multicolumn{5}{|c|}{ Abnormal stapedius reflex ${ }^{d}$} \\
\hline Unilateral & $5(11)$ & $3(11)$ & $2(14)$ & $0(0)$ \\
\hline Bilateral & $27(60)$ & $16(57)$ & $8(57)$ & $3(100)$ \\
\hline \multicolumn{5}{|l|}{ Type of hearing loss } \\
\hline Conductive & $15(33)$ & $12(43)$ & $3(21)$ & $0(0)$ \\
\hline Sensorineural & $1(2)$ & $1(4)$ & $0(0)$ & $0(0)$ \\
\hline Mixed & $8(18)$ & $1(4)$ & $4(29)$ & $3(100)$ \\
\hline \multicolumn{5}{|c|}{$d B$ decibel } \\
\hline \multicolumn{5}{|c|}{ a Based on PTA over $0.25,0.5,1,2,4,6$ and $8 \mathrm{kHz}$} \\
\hline \multicolumn{5}{|c|}{${ }^{\mathrm{b}}$ Based on PTA over $0.5,1,2$ and $4 \mathrm{kHz}$ (BE PTA4) } \\
\hline \multicolumn{5}{|l|}{${ }^{\circ}$ Defined as Type B or C } \\
\hline & & & & \\
\hline
\end{tabular}

findings were in accordance with the findings assessed by pure-tone audiometry.

Hearing loss in the better ear (BE PTA4 $\geq 20 \mathrm{~dB}$ HL) was found in $42 \%(19 / 45)$ of the participants: in $32 \%$ (9/28) of the youngest age group, and 50\% (7/14) of those aged 45-64 year. The majority (15/19) had mild hearing loss, while four had disabling hearing loss (hearing threshold $\geq 35 \mathrm{~dB}$ HL).

\section{Impedance audiometry}

An abnormal tympanometry (Type B or C) in at least one ear was found in $71 \%(32 / 45)$ of the participants (Table 2), of whom 18\% (8/45) were unilateral. All with an abnormal tympanometry also had hearing loss. An abnormal stapedius reflex in at least one ear were found in $71 \%(32 / 45)$ of the participants, of whom $11 \%(5 / 45)$ were unilateral (Table 2).

\section{Type of hearing loss}

Of those with hearing loss, 63\% (15/24) had a conductive hearing loss, $4 \%(1 / 24)$ had a sensorineural hearing loss, and $33 \%(8 / 24)$ had a mixed hearing loss (Table 2 ). One male participant had profound unilateral hearing loss (hearing threshold $84 \mathrm{~dB}$ HL) due to previous acute trauma to the ear. None of the participants reported prior occupational noise exposure.

\section{Discussion}

In this population-based study, over half of Norwegian adults with achondroplasia had hearing loss $(\geq 20$ $\mathrm{dB} \mathrm{HL}$ ) in at least one ear, including half of the youngest age group (age 16-44 years). There was no considerable difference between men and women. The majority 


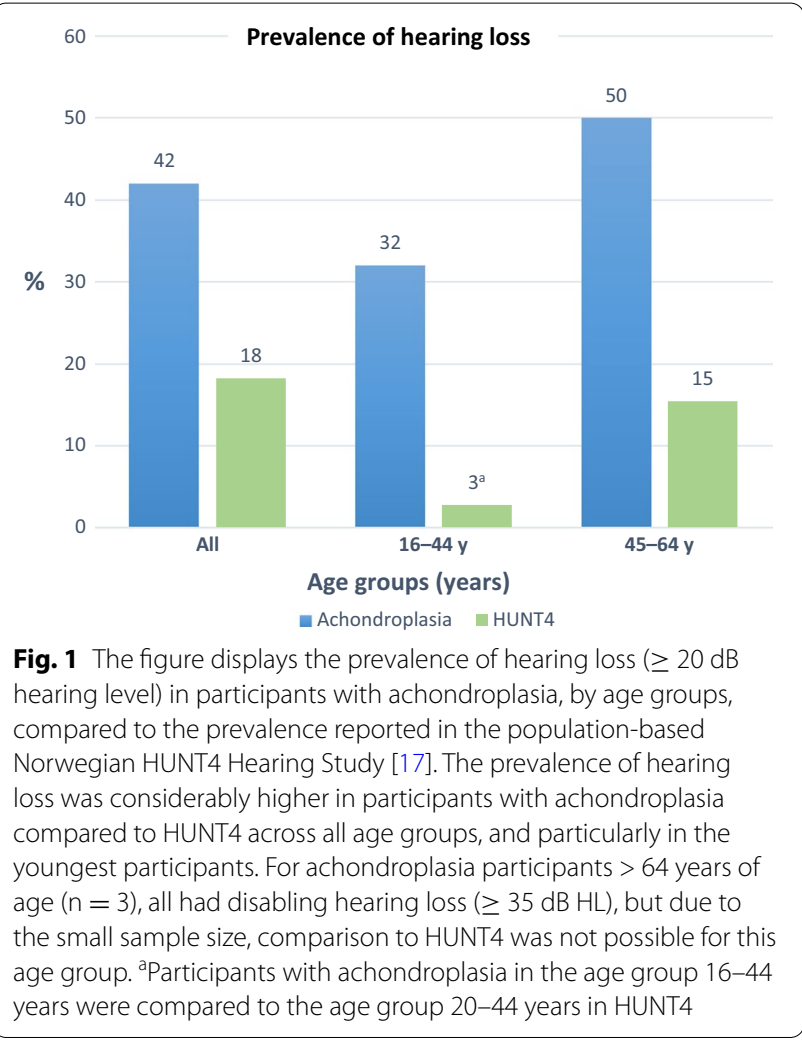

had conductive hearing loss. An abnormal tympanogram (Type B or C) in at least one ear was found in over $70 \%$ of the participants.

To our knowledge, this is the largest clinical study to date investigating hearing loss in adults with achondroplasia and performed under standardized conditions. Our findings are consistent with prior studies, having reported a prevalence of hearing loss of about $55-60 \%$ in adults with achondroplasia $[13,15]$.

We compared our data to the Norwegian HUNT4 Hearing study, both based on BE PTA4 [17]. The prevalence of hearing loss was considerably higher in the achondroplasia study population compared to HUNT4 across all age groups, and particularly in the youngest age group (Fig. 1). In participants with achondroplasia aged $16-44$ years, $32 \%$ had hearing loss, compared to $3 \%$ in the HUNT4 population (20-44 years). In the age group 45-64 years, $50 \%$ of the achondroplasia participants had hearing loss, compared to $15 \%$ in HUNT4. Only three achondroplasia participants were over 64 years, all with disabling hearing loss, compared to $18 \%$ with disabling hearing loss in this age group in the HUNT4 study [17].

Hearing loss may have a considerable negative impact on the ability to participate in social activities, and may cause social isolation and reduce educational attainments and employment opportunities [16, 18, 31]. Even mild hearing loss can cause great difficulty in hearing and understanding another person talking in a noisy place, for instance on an urban street, or in a social setting with many people [16, 29]. Also those with a unilateral hearing loss may have difficulties in following or taking part in a conversation [29].

More than $80 \%$ of our study participants reported having had at least one episode of acute otitis during childhood, and almost half had a history of adenoidectomy. These findings are consistent with a recent US study by Okenfuss et al., where $74 \%$ of the participants reported recurrent episodes $(\geq 3)$ of otitis media infection, and $40 \%$ had undergone adenoidectomy [11]. In a study by Ireland et al., $50 \%$ of the children had ventilation tubes inserted before the age of 3 years, consistent with $44 \%$ observed in our study [32].

The majority of those diagnosed with hearing loss in our study had conductive hearing loss, consistent with prior studies in achondroplasia [7, 11, 15]. Conductive hearing loss is commonly caused by middle ear effusion due to Eustachian tube dysfunction [5, 20], as was also reflected by the abnormal tympanometry (Type B or C) and stapedius reflex observed in over $70 \%$ of our study participants. Occupational noise exposure is another risk factor associated with hearing loss in adults [20]. However, none of the study participants reported prior exposure to occupational noise, so this is unlikely to explain the high prevalence of hearing loss in our study population.

In average statured persons, hearing loss is usually more prevalent in men than in women, across all age groups $[17,33]$. In contrast, there was no considerably difference in hearing loss between men and women in our achondroplasia study population, likely because the abnormal craniofacial skull anatomy is present in both men and women with achondroplasia [3, 7].

While over half of the participants in our study had hearing loss, only $20 \%$ were currently using hearing aids. This proportion is comparable to studies conducted on average stature populations [20,31]. In the general population, low confidence in effectiveness, high costs, lack of comfort, social norms, or cosmetic appearance are possible causes reported for the low use of hearing aids [20,34]. These causes are probably applicable to adults with achondroplasia as well. Impaired hearing might also get less attention in achondroplasia due to the high prevalence of other potential severe medical complications, as well as the daily challenges commonly experienced by persons with this condition [10, 11, 24, 35-37]. 


\section{Clinical implications}

The present study demonstrated a high prevalence of hearing loss in adults with achondroplasia. Of particular notice was the high prevalence of hearing loss observed in young persons with achondroplasia, consistent with prior studies $[7,9,11]$. These findings highlight the importance of a regular hearing assessment and adequate management and follow-up of acute and chronic middle ear disease during childhood in achondroplasia [10, 12, 23]. This should also include a low threshold for referral to an otolaryngologist in cases of recurrent otitis media, speech delay, or suspicion of chronic otitis media, in order to treat properly, and decrease the risk of permanent hearing loss $[5,12,23$, 38].

Our findings indicate that hearing loss might be underdiagnosed and undertreated in adults with achondroplasia, underlining the importance of a formal hearing assessment being conducted also in adolescents and young adults with this condition [23]. Further follow-up should be individualized, and with a low threshold for a subsequent hearing assessment if suspicion of impaired hearing is present.

Hearing loss may have a negative effect on work participation and educational achievements, and compensating strategies are strenuous and can cause tiredness [31]. In adult patients diagnosed with hearing loss, an evaluation by an otolaryngologist should be considered, and the need for hearing aids, assistive listening devices, and workplace and educational accommodations should be discussed. A variety of hearing aids and hearing assistive technology are available [20,31, 34]. Also the acoustic environment and potential need for noise reducing measures should be considered, as well as flexibility regarding organizing the workday and tasks, how meetings and dialogues at work are organized, and the possibility of taking breaks when needed [31, 39]. This also applies to students at college or university, to facilitate optimal educational outcomes [40].

\section{Strengths and limitations}

Strengths of this study are the population-based study sample, all having genetically confirmed achondroplasia, and a comprehensive audiologic assessment conducted in all participants. Other strengths are that all hearing assessments were conducted by an experienced investigator and in accordance with current international reference standards.

There are also limitations to this study. First, there were few participants in the oldest age group over 64 years of age. In the general population, hearing loss increases with age $[17,21]$. As we probably have recruited a larger proportion of younger adults with achondroplasia in the present study, the overall prevalence rate of hearing loss in our study may be underestimated.

Second, the exact prevalence of achondroplasia within Norway is uncertain. We have estimated the population of adults (16 years or older) with achondroplasia in Norway to be between 66 and 101 adults [24]. As this study included somewhat fewer participants, there is a risk of selection bias that could have affected the present outcomes. However, except for few participants in the oldest age group, there was an even distribution regarding gender, age, and geographical residence in the study population.

Finally, our study population consisted only of Caucasian participants, although this was not an inclusion criterion. Prevalence rates of hearing loss might be different in achondroplasia populations of other ethnicity, although the medical complication rates, including otitis media infections, seem to be relatively consistent across achondroplasia study populations of different geographical origin [9-11, 41, 42].

\section{Conclusions}

This population-based study has demonstrated that adults with achondroplasia are at increased risk of early hearing loss, in contrast to the general population where hearing loss largely is caused by ageing. The high prevalence of early hearing loss underlines the importance of a regular hearing assessment being part of standard care in achondroplasia, including adolescents and young adults. In adult patients diagnosed with hearing loss, an evaluation by an otolaryngologist should be considered, and the need for hearing aids, assistive listening devices, and workplace and educational accommodations should be discussed. New precision therapies aimed at restoring normal endochondral ossification are now in final clinical development for children with achondroplasia [2, 43], and it will be interesting to see if these therapies decrease the incidence of hearing loss in this population.

\footnotetext{
Acknowledgements

We would like to thank the Norwegian Restricted Growth Association for their collaboration and support in the project, and the Dam Foundation for funding the Norwegian Adult Achondroplasia Study. Most of all, thanks to all the participants for their time and effort in participating in the study.

\section{Authors' contributions}

SOF initiated and planned the study, was the principal investigator, project leader, did the statistical analysis, and wrote the draft manuscript together with JS. JS conducted all the hearing measurements, developed the SPSS database, and entered the data into SPSS. HB and BÅ participated in planning and conducting the study, including the clinical examination and photo documentation, and revised the final manuscript. RS contributed to the supervision, including writing and revision of the manuscript. The corresponding author confirms that all listed authors meet authorship criteria and that no others meeting the criteria have been omitted. SOF affirms the manuscript is an honest, accurate, and transparent account of the study being reported. All authors read and approved the final manuscript.
} 


\section{Funding}

This work was supported by the Dam Foundation (Project Number 2019/ FO249324), but the funding source had no part in planning of the study, data collection or reporting of the results.

\section{Availability of data and materials}

De-identified individual participant data are available from the corresponding author on reasonable request.

\section{Declarations}

\section{Ethics approval and consent to participate}

The study was approved by the Regional Committee for Medical and Health Research Ethics (REK) South-East, Norway (approval number 2016/2271), and is registered on ClinicalTrials.gov (NCT03780153). The study was conducted in accordance with the Helsinki Declaration for medical research, and all participants gave their informed, written consent prior to participation.

\section{Consent for publication}

All authors read and approved the final manuscript.

\section{Competing interests}

The authors have completed the ICMJE form and declare that they have no competing interests.

\section{Author details}

1TRS National Resource Centre for Rare Disorders, Sunnaas Rehabilitation Hospital, 1450 Nesodden, Norway. ${ }^{2}$ Faculty of Medicine, Institute of Clinical Medicine, University of Oslo, Oslo, Norway. ${ }^{3}$ Department of Hearing, Lovisenberg Diaconal Hospital, Oslo, Norway. ${ }^{4}$ Victorian Clinical Genetics Services, Murdoch Children's Research Institute, University of Melbourne, Parkville, Australia.

\section{Received: 31 August 2021 Accepted: 24 October 2021}

Published online: 04 November 2021

\section{References}

1. Horton WA, Hall JG, Hecht JT. Achondroplasia. Lancet. 2007;370(9582):162-72

2. Legeai-Mallet L, Savarirayan R. Novel therapeutic approaches for the treatment of achondroplasia. Bone. 2020;141:115579.

3. Lyford-Pike S, Hoover-Fong J, Tunkel DE. Otolaryngologic manifestations of skeletal dysplasias in children. Otolaryngol Clin N Am. 2012;45(3):579-98.

4. Tan HL, Kheirandish-Gozal L, Abel F, Gozal D. Craniofacial syndromes and sleep-related breathing disorders. Sleep Med Rev. 2016;27:74-88.

5. Rosenfeld RM, Shin JJ, Schwartz SR, Coggins R, Gagnon L, Hackell JM, et al. Clinical practice guideline: otitis media with effusion (update). Otolaryngol Head Neck Surg. 2016;154(1 Suppl):1-s41.

6. Pauli RM. Achondroplasia: a comprehensive clinical review. Orphanet J Rare Dis. 2019;14(1):1.

7. Collins WO, Choi SS. Otolaryngologic manifestations of achondroplasia. Arch Otolaryngol. 2007;133(3):237-44

8. Julliand S, Boule M, Baujat G, Ramirez A, Couloigner V, Beydon N, et al. Lung function, diagnosis, and treatment of sleep-disordered breathing in children with achondroplasia. Am J Med Genet A. 2012;158a(8):1987-93.

9. Hunter AG, Bankier A, Rogers JG, Sillence D, Scott CI Jr. Medical complications of achondroplasia: a multicentre patient review. J Med Genet. 1998;35(9):705-12.

10. Wright MJ, Irving MD. Clinical management of achondroplasia. Arch Dis Child. 2012:97(2):129-34.

11. Okenfuss E, Moghaddam B, Avins AL. Natural history of achondroplasia: a retrospective review of longitudinal clinical data. Am J Med Genet A 2020;182:2540-51.

12. Savarirayan $R$, Tunkel DE, Sterni LM, Bober MB, Cho TJ, Goldberg MJ, et al Best practice guidelines in managing the craniofacial aspects of skeletal dysplasia. Orphanet J Rare Dis. 2021;16(1):31.
13. Tunkel $D$, Alade $Y$ Kerbavaz $R$, Smith $B$, Rose-Hardison $D$, HooverFong J. Hearing loss in skeletal dysplasia patients. Am J Med Genet A. 2012:158a(7):1551-5.

14. Fredwall SO, Maanum G, Johansen H, Snekkevik H, Savarirayan R, Lidal IB. Current knowledge of medical complications in adults with achondroplasia: a scoping review. Clin Genet. 2020;97(1):179-97.

15. Glass L, Shapiro I, Hodge SE, Bergstrom L, Rimoin DL. Audiological findings of patients with achondroplasia. Int J Pediatr Otorhinolaryngol. 1981:3(2):129-35.

16. GBD 2019 Hearing Loss Collaborators. Hearing loss prevalence and years lived with disability. 1990-2019: findings from the Global Burden of Disease Study 2019. Lancet. 2021;397(10278):996-1009.

17. Engdahl B, Strand BH, Aarhus L. Better hearing in Norway: a comparison of two HUNT Cohorts 20 years apart. Ear Hear. 2020;42(1):42-52.

18. Wilson BS, Tucci DL, Merson MH, O'Donoghue GM. Global hearing health care: new findings and perspectives. Lancet. 2017;390(10111):2503-15.

19. Bagai A, Thavendiranathan P, Detsky AS. Does this patient have hearing impairment? JAMA. 2006;295(4):416-28.

20. Cunningham LL, Tucci DL. Hearing loss in adults. N Engl J Med. 2017:377(25):2465-73.

21. Homans NC, Metselaar RM, Dingemanse JG, van der Schroeff MP, Brocaar $\mathrm{MP}$, Wieringa $\mathrm{MH}$, et al. Prevalence of age-related hearing loss, including sex differences, in older adults in a large cohort study. Laryngoscope. 2017:127(3):725-30.

22. Global regional. national incidence, prevalence, and years lived with disability for 310 diseases and injuries, 1990-2015: a systematic analysis for the Global Burden of Disease Study 2015. Lancet. 2016;388(10053):1545-602.

23. Hoover-Fong J, Scott Cl, Jnes MC. Health supervision for people with achondroplasia. Pediatrics. 2020;145(6):e20201010.

24. Fredwall SO, Steen U, de Vries O, Rustad CF, Eggesbø HB, Weedon-Fekjær $\mathrm{H}$, et al. High prevalence of symptomatic spinal stenosis in Norwegian adults with achondroplasia: a population-based study. Orphanet J Rare Dis. 2020;15(1):123.

25. Øygarden J. Norwegian Speech Audiometry. Doctoral thesis. Doktoravhandlinger ved NTNU, 1503-8181; 2009:68.

26. Onusko E. Tympanometry. Am Fam Phys. 2004;70(9):1713-20.

27. Margolis $\mathrm{RH}$. Detection of hearing impairment with the acoustic stapedius reflex. Ear Hear. 1993;14(1):3-10.

28. Katz J. Handbook of clinical audiology. 7th ed. Alphen aan den Rijn: Wolters Kluwer; 2014

29. Olusanya BO, Davis AC, Hoffman HJ. Hearing loss grades and the International classification of functioning, disability and health. Bull World Health Organ. 2019;97(10):725-8.

30. Stevens G, Flaxman S, Brunskill E, Mascarenhas M, Mathers CD, Finucane M. Global and regional hearing impairment prevalence: an analysis of 42 studies in 29 countries. Eur J Public Health. 2013;23(1):146-52.

31. Svinndal EV, Solheim J, Rise MB, Jensen C. Hearing loss and work participation: a cross-sectional study in Norway. Int J Audiol. 2018:57(9):646-56.

32. Ireland PJ, Johnson S, Donaghey S, Johnston L, Ware RS, Zankl A, et al. Medical management of children with achondroplasia: evaluation of an Australasian cohort aged 0-5 years. J Paediatr Child Health. 2012:48(5):443-9.

33. Blackwell DL, Lucas JW, Clarke TC. Summary health statistics for U.S adults: National Health Interview Survey, 2012. Vital Health Stat. 2014;10(260):1-161.

34. Lasak JM, Allen P, McVay T, Lewis D. Hearing loss: diagnosis and management. Prim Care. 2014:41(1):19-31.

35. Hoover-Fong JE, Alade AY, Hashmi SS, Hecht JT, Legare JM, Little ME, et al. Achondroplasia Natural History Study (CLARITY): a multicenter retrospective cohort study of achondroplasia in the United States. Genet Med. 2021:23(8):1498-505.

36. Shakespeare T, Thompson S, Wright M. No laughing matter: medical and social experiences of restricted growth. Scand J Disabil Res. 2010;12(1):19-31.

37. Constantinides C, Landis SH, Jarrett J, Quinn J, Ireland PJ. Quality of life, physical functioning, and psychosocial function among patients with achondroplasia: a targeted literature review. Disabil Rehabil. 2021:1-13. https://doi.org/10.1080/09638288.2021.1963853. 
38. Aarhus L, Tambs K, Kvestad E, Engdahl B. Childhood otitis media: a cohort study with 30-year follow-up of hearing (The HUNT Study). Ear Hear. 2015;36(3):302-8.

39. Svinndal EV, Jensen C, Rise MB. Working life trajectories with hearing impairment. Disabil Rehabil. 2020;42(2):190-200.

40. Bell D, Foiret J. A rapid review of the effect of assistive technology on the educational performance of students with impaired hearing. Disabil Rehabil Assist Technol. 2020;15(7):838-43.

41. Ireland PJ, Pacey V, Zankl A, Edwards P, Johnston LM, Savarirayan R. Optimal management of complications associated with achondroplasia. Appl Clin Genet. 2014;7:117-25.

42. Chen G, Fu S, Dong J, Zhang L. Otologic and audiologic characteristics of children with skeletal dysplasia in central China. Acta Otolaryngol. 2013;133(7):728-32
43. Savarirayan R, Tofts L, Irving M, Wilcox W, Bacino CA, Hoover-Fong J, et al. Once-daily, subcutaneous vosoritide therapy in children with achondroplasia: a randomised, double-blind, phase 3, placebo-controlled, multicentre trial. Lancet. 2020;396(10252):684-92.

\section{Publisher's Note}

Springer Nature remains neutral with regard to jurisdictional claims in published maps and institutional affiliations.
Ready to submit your research? Choose BMC and benefit from:

- fast, convenient online submission

- thorough peer review by experienced researchers in your field

- rapid publication on acceptance

- support for research data, including large and complex data types

- gold Open Access which fosters wider collaboration and increased citations

- maximum visibility for your research: over $100 \mathrm{M}$ website views per year

At BMC, research is always in progress.

Learn more biomedcentral.com/submissions 